\title{
Occlusive dressing-induced secretomes influence the migration and proliferation of mesenchymal stem cells and fibroblasts differently
}

\author{
Michael K. Cerny ${ }^{1 *}$, Ursula Hopfner ${ }^{1}$, Manuela Kirsch¹, Elisabeth-Maria Haas ${ }^{2}$, Fan Wu' ${ }^{1}$, Riccardo Giunta ${ }^{2}$,
} Hans-Guenther Machens ${ }^{1}$, Dominik Duscher ${ }^{1}$, Holger Erne ${ }^{1 \dagger}$ and Arndt F. Schilling ${ }^{3^{*}+}$

\begin{abstract}
Background: Fingertip injuries treated with occlusive dressings (ODs) lead to nearly scar-free, functionally, and aesthetically pleasing results. We hypothesized that paracrine factors in the wound fluid (secretome) may influence migration and proliferation of mesenchymal stem cells (MSCs) and fibroblasts and modulate the wound-healing process.

Methods: We could collect wound fluid samples from 4 fingertip injuries and 7 split skin donor sites at the 5 th day during dressing change. Blood serum samples served as controls. The proliferation rate of MSCs and fibroblasts (HS27) was continuously measured through impedance analysis for $60 \mathrm{~h}$ and by Alamarblue analysis after $72 \mathrm{~h}$. Cell migration was evaluated continuously for $15 \mathrm{~h}$ and confirmed by the in vitro wound-healing assay.

Results: Migration of MSCs under the influence of both wound fluids was significantly faster than controls from 4 to $6 \mathrm{~h}$ after incubation and reversed after $9 \mathrm{~h}$. MSC proliferation in wound fluid groups showed a significant increase at 5 and $10 \mathrm{~h}$ and was significantly decreased after $45 \mathrm{~h}$. Fibroblasts in wound fluid groups showed overall a significant increase in migration and a significant decrease in proliferation compared to controls.
\end{abstract}

Conclusion: OD-induced secretomes influence MSCs and fibroblasts and thereby possibly modulate wound healing and scar tissue formation.

Keywords: Occlusive dressings, Fingertip injuries, MSC, Scar

\section{Background}

Adult wound healing aims at rapidly closing a defect and reestablishing the skin barrier to prevent any further infection and fluid loss [1]. This process is commonly divided into at least three overlapping stages:

\footnotetext{
*Correspondence: m.cerny@tum.de;

Arndt.Schilling@med.uni-goettingen.de

${ }^{+}$Holger Erne and Arndt F. Schilling contributed equally and share last authorship

${ }^{1}$ Department for Plastic Surgery and Hand Surgery, Klinikum Rechts der Isar, Technical University Munich, Ismaninger Str.22, 81675 Munich, Germany

${ }^{3}$ Department for Trauma Surgery, Orthopedic Surgery and Plastic Surgery, University Medical Center Goettingen, Goettingen, Germany Full list of author information is available at the end of the article
}

inflammation, proliferation, and remodeling [2]. In inflammation, after initial hemostasis by the aggregation of platelets, the release of chemoattractants and growth factors recruits fibroblasts and leukocytes [2]. In proliferation, granulation tissue is predominantly formed by fibroblasts and macrophages, creating a new extracellular matrix, which allows epithelization, angiogenesis, and fibroplasia to take place [3]. Finally, in remodeling, collagen type III is replaced with collagen type I, resulting in a stable scar [3]. This whole process is reparative rather than regenerative, as the final scar tissue is a disturbance of the normal skin function, structure, and architecture with a reduced tensile strength by about $20-30 \%[4,5]$. 
In general, a scar is composed of excess extracellular matrix (ECM) compared to normal, uninjured dermal tissue and is devoid of epidermal appendages [5]. Purely regenerative healing of an inflicted wound in humans occurs in fetal wound healing up to 24 weeks of gestation [6]. It was demonstrated that fetal wounds differ from adult wounds in inflammatory response, gene expression, growth factor release as well as extracellular matrix production [7]. In scars, the extracellular matrix of the new dermis is abnormally deposited as small parallel bundles of collagen types I, III and fibronectin. In the non-injured skin, these bundles are large and appear in a basketweave orientation, suggesting a structural problem in the regenerative process [8]. Adult tissue loses the regenerative capacity and clinical problems owing to scars are manifold, including pathologies like keloids and hypertrophic scars, as well as symptoms like itching, pain or inhibition of movement due to contractions of joints [9].

However, also in adult wound healing, there are certain types of wounds which can heal nearly scar-free, resulting in a good aesthetic and functional outcome. Fingertip injuries treated with occlusive dressings (ODs) may regenerate up to $90 \%$ of the initial soft tissue loss, regenerate dermal ridges, and result in a good sensibility of the previously injured skin [10]. ODs create a moist wound environment and seem to play a key role for the favorable results seen in non-surgically treated fingertip amputations. As early as 1965, the effect of occlusive dressings was compared to air-exposed healing in human skin wounds by Hinman et al. [11]. In 1983, Soderberg et al. compared fingertip injuries treated with adhesive zinc tape dressings to surgical therapies. The authors found a better 2-point-discrimination sensitivity, as well as less scars and pain in patients treated with dressings alone [12]. Mennen and Wiese treated 200 patients with fingertip injuries with semi-occlusive dressings and reported excellent results, a near normal fingertip shape and a comparable sensitivity to the non-injured hand in between 20 and 30 days after the injury [13].

ODs allow the development of a moist wound environment, which immerses the cells and has been shown to increase collagen synthesis and to accelerate the rate of re-epithelialization $[14,15]$. We hypothesized that the pivotal factor triggering such pro-regenerative stimuli underneath ODs is a direct effect of the wound fluid. This wound fluid is the sum of all biological substances, secreted from the sterile wound, and contains the secretome of the cells in the wound area. We have shown before that this secretome can change under wound conditions and can modulate wound-healing processes like angiogenesis [16-18].

In this study, we investigated the influence of such wound fluid from ODs on the behavior of mesenchymal stem cells (MSCs) and fibroblasts (FBs), important modulators of the wound-healing process.

\section{Methods}

The study protocol conformed to the guidelines of the 1975 Declaration of Helsinki as reflected in the approval of our local ethics committee (No. 527/15). 4 Fingertip injuries (Allen stages II-III) were treated with occlusive dressings (Smith \& Nephew IV3000) after initial wound care. In addition, we treated 7 split skin donor site wounds (at the ventro-medial to ventro-lateral upper leg of the patients) with the same occlusive dressings postoperatively. At the 5th day, we tried to harvest fluid samples after obtaining informed consent from any patient while changing the dressings. This was done with a small syringe puncturing the dressing without injuring the patient's skin. The fingertip injuries were dressed leaving a small reservoir at the top to allow a fluid collection, as is necessary for the functionality of the therapy (see Fig. 1) $[19,20]$. We collected fluid from 4 fingertip injuries from 4 patients (minimum $60 \mu \mathrm{l}$, median $91 \mu \mathrm{l}$, and maximum $120 \mu \mathrm{l}$ ) and 7 split skin donor sites from 7 patients (minimum $3800 \mu \mathrm{l}$, median $2700 \mu \mathrm{l}$, and maximum 11,200 $\mu \mathrm{l}$ ). Both patient groups had comparable demographics with an average age of 53 years in the fingertip group (range $52-55$ ) and 55 years in the split skin group (range 39-82) without any comorbidities. The male-to-female ratio was 2:2 in the fingertip group and 2:5 in the split skin group.

Blood serum from each patient was drawn as controls (minimum $800 \mu \mathrm{l}$, median $2000 \mu \mathrm{l}$, and maximum $2500 \mu \mathrm{l})$. Due to limitations of fluid quantity per sample, we used 4 fingertip fluid samples and 4 of the 7 split

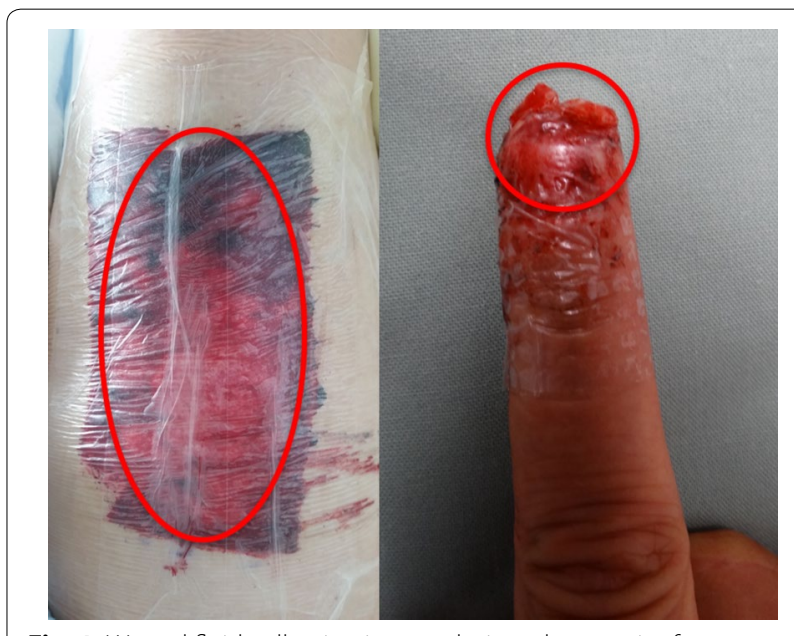

Fig. 1 Wound fluid collection in a predesigned reservoir of an occlusive wound dressing of a patient with split skin donor site (left) and a fingertip amputation (right) (in the red circle) 
skin fluid samples with respective blood serum controls in the Alamarblue Assay and xCELLigence analysis. The remaining 3 split skin donor site samples were analyzed in the in vitro wound-healing assay (Ibidi, Germany).

\section{Cell culture}

HS-27, a commercially available human derived fibroblast cell line (ATCC-LGC Standards, Germany), was cultured in DMEM (Biochrom, Germany) supplemented with 10\% FCS. HS-27 cells are human foreskin fibroblasts which are growing adherent to cell-culture plastic. We used adipose-derived MSCs also known as adiposederived stem cells (ASCs or ADSCs) isolated from aesthetic liposuction, as previously described [21]. The cells were characterized in our lab by their expression of CD73, CD90, and CD105 as well as their potency to differentiate into fat cell, chondrocytes, and osteoblasts. For cultivation, MEM-alpha (Biochrom, Germany), containing $10 \%$ FCS was used.

\section{Cell metabolism assay (Alamarblue)}

MSCs were seeded in a density of 8000 cells/well and HS-27 FBs in a density of 4000 cells/well in 96 well plates using standard cultivation media as described above. Cells were allowed to attach overnight, then the medium was replaced with sample (wound fluid or serum) in a concentration of $10 \%$. Alamarblue assay (Sigma-Aldrich) was performed after 3 days of incubation at $37{ }^{\circ} \mathrm{C}$ in $5 \%$ $\mathrm{CO}_{2}$ atmosphere according to the instructions of the manufacturer. In short, Alamarblue reagent was added to the cells and incubated for $30 \mathrm{~min}$, followed by fluorescence measurement at Ex $530 \mathrm{~nm} / \mathrm{Em} 600 \mathrm{~nm}$.

\section{Impedance proliferation assay (xCELLigence)}

The xCELLigence device enables the continuous analysis of cell proliferation. The proliferation rates of MSCs and HS27 fibroblasts were determined with the xCELLigence-DP Analyser $\left(\right.$ OLS $^{\circledR}$ Omni Life Sciences, Germany). We seeded 4000 HS-27 FBs and 8000 MSCs in individual wells and incubated them with standard cultivation medium for $40 \mathrm{~h}$. Wound fluid or serum was prediluted 1:10 in standard medium before it was added to the seeded wells in a ratio of $1: 1$ to achieve a final sample concentration of $5 \%$. Continuous measurement of impedance (Cell index) started $30 \mathrm{~min}$ after seeding and was performed in intervals of $15 \mathrm{~min}$ for $100 \mathrm{~h}$. Analysis was done for the first $60 \mathrm{~h}$.

\section{Impedance migration assay (xCELLigence)}

Migration analysis was performed in CIM plates in combination with xCELLigence-DP-Analyzer $\left(\mathrm{OLS}^{\circledR}\right.$
Omni Life Sciences). The CIM plate consists of an upper chamber with a porous membrane and a lower chamber. 40,000 HS-27 FBs or MSCs were seeded in standard medium in the wells of the upper chamber and left for $30 \mathrm{~min}$ to settle. As chemoattractant $5 \%$ wound exudate or $5 \%$ serum, diluted in standard medium, was filled in the wells of the lower chamber. Impedance measurement at the lower side of the porous membrane was carried out to visualize cell migration from the upper to the lower chambers. Impedance read out was expressed as cell index and executed every $15 \mathrm{~min}$ to a maximum of $25 \mathrm{~h}$. Analysis was done for the first $15 \mathrm{~h}$.

\section{In vitro wound-healing assay (Ibidi)}

We first pipeted $70 \mu \mathrm{l}$ cell suspension $\left(1.2 \times 10^{5}\right.$ cells $\left./ \mathrm{ml}\right)$ in each of the 24 wells of Ibidi culture inserts (Ibidi, Germany). Next, cells were incubated at $37^{\circ} \mathrm{C}$ and $5 \% \mathrm{CO}_{2}$ for $24 \mathrm{~h}$ to obtain a confluent cell layer. Culture inserts were removed afterwards and cell layers washed with PBS. Filled plate wells were prepared with culture medium (Dulbecco's MEM by Merck Millipore, 2\% wound fluid and $1 \%$ antibiotic/antimycotic ingredient by Capricorn, AAS-B) up to $500 \mu$ l. Wells filled with medium without wound fluid were used as negative controls. Microscopy pictures were taken at $0 \mathrm{~h}, 6 \mathrm{~h}, 12 \mathrm{~h}$, and $24 \mathrm{~h}$ and images were analyzed using the WimScratch software.

\section{The statistical analysis}

Data are shown as mean \pm SEM. Statistical analysis between the groups was performed using unpaired $t$ tests. $p$ values of less than 0.05 were considered statistically significant.

\section{Results}

\section{Migration assay (xCELLigence impedance)}

The migration of MSCs under the influence of fingertip fluid measured with xCELLigence was significantly increased at $4 \mathrm{~h}(p=0.046), 5 \mathrm{~h}(p=0.032)$ and $6 \mathrm{~h}(p=0.048)$ compared to blood serum controls of the same patients. This effect reversed significantly in the MSC population of occlusive treated fingertip injuries after $11 \mathrm{~h}(p=0.047)$ and continued afterwards (see Fig. 2). MSCs under the influence of split skin fluid showed initially a trend towards an increased migration compared to respective serum controls, which was not significant. A significant decrease of MSC migration, influenced by split skin donor site fluid, was found starting at $9 \mathrm{~h}$ after incubation $(p=0.049)$ and continued to do so (see Fig. 2). Combined analysis of MSC migration of both wound fluids compared to both serum controls showed a significant increase from $3 \mathrm{~h}(p=0.023)$ to $6 \mathrm{~h}$ $(0.017)$ with the strongest increase at $4 \mathrm{~h}(p=0.001)$. 


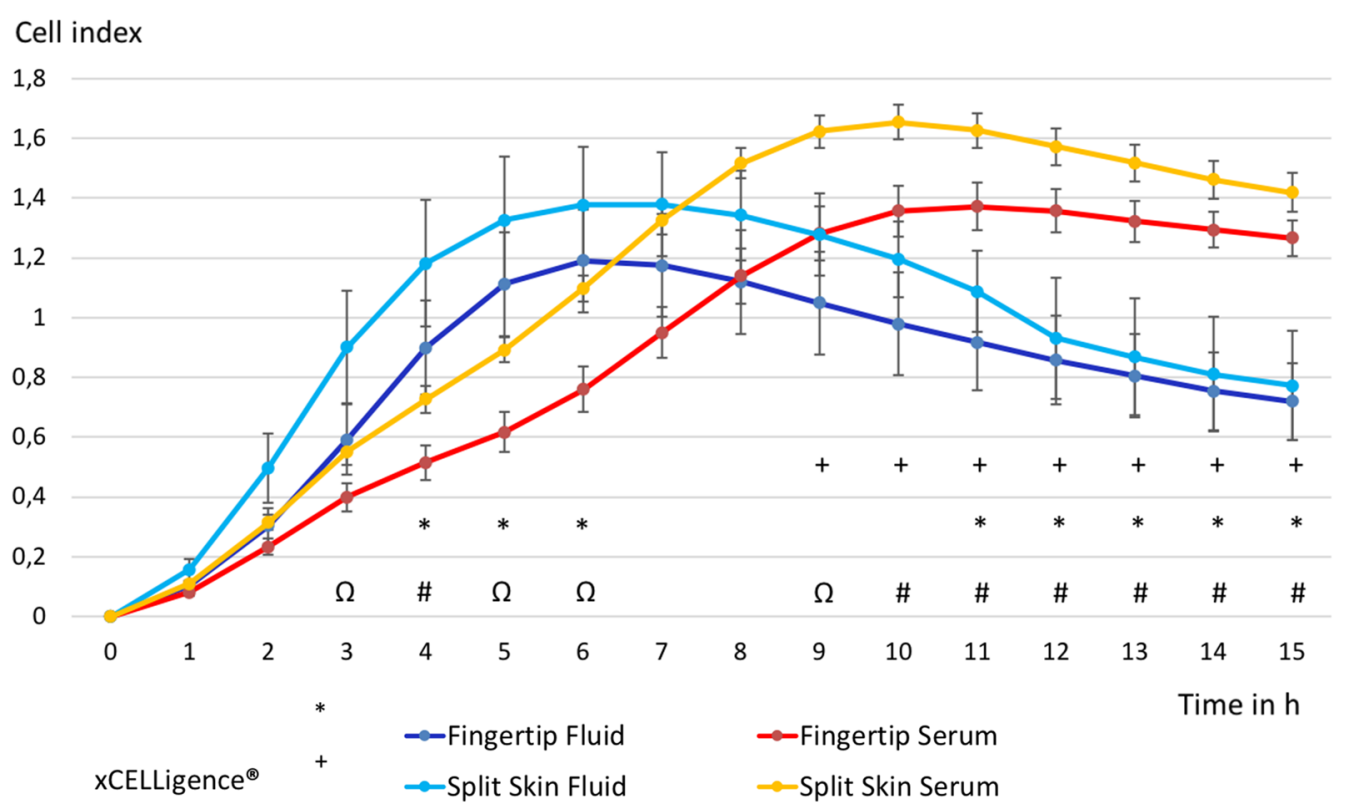

Fig. 2 Time-dependent MSC migration in wound fluid groups vs. control groups. All groups in mean \pm SEM. * $p<0.05$ mean fingertip fluids vs. mean fingertip serums. ${ }^{+} p<0.05$ mean split skin fluids vs. mean split skin serums. ${ }^{\#} p<0.01, \Omega p<0.05$ mean all fluids vs. mean all serums

A significant decrease in MSC migration of all fluids compared to all serum values started at $9 \mathrm{~h}(p=0.034)$ onwards (see Fig. 2).

The migration of HS27-FBs of fingertip fluids in xCELLigence was significantly increased at $5 \mathrm{~h}(p=0.041)$, $6 \mathrm{~h}(p=0.043)$ and $7 \mathrm{~h}(p=0.049)$ compared to respective serum controls (see Fig. 3). The migration of HS27
FBs of split skin fluid alone did not show any significant changes, but mimicked the curve of the fingertip fluid values with a less steep increase and decline after a few hours. Analyzing the migration HS27 FBs of all wound fluid samples compared to all serum samples showed a significant increase between 5 and $10 \mathrm{~h}$ after sample incubation $(p=0.004)$ (see Fig. 3).

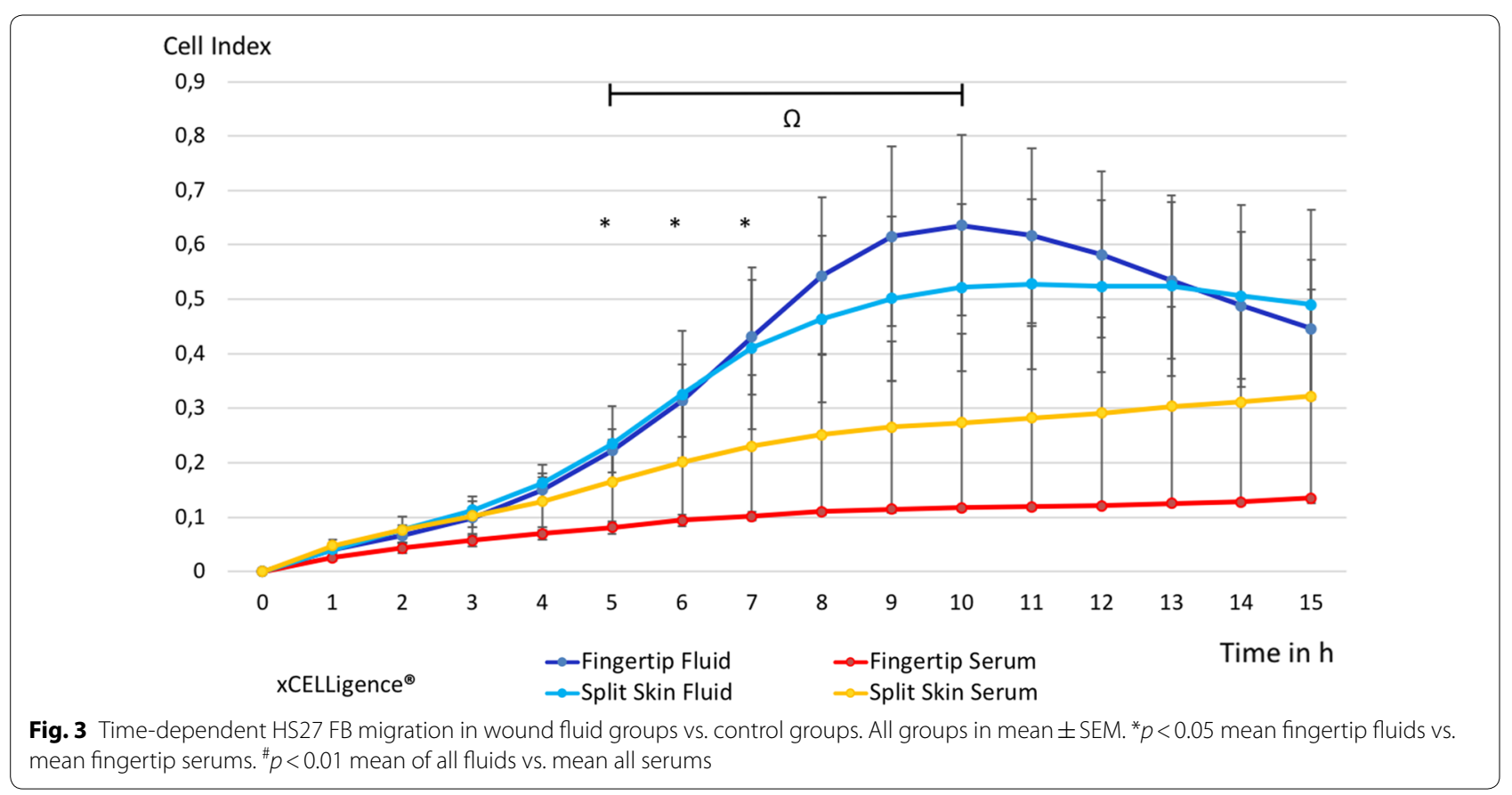




\section{In vitro wound-healing assay}

The in vitro wound-healing assay showed a significantly increased HS27 FB migration at $12 \mathrm{~h}(p=0.012)$ and at $24 \mathrm{~h}(p=0.017)$ compared to the control, supporting our data from the impedance analysis (see Figs. 4, 5).

\section{Proliferation I (xCELLigence impedance)}

We observed a non-significant increase of cell proliferation of MSCs exposed to each fluid alone at $5 \mathrm{~h}$ (fingertips $p=0.061$, split skin donor sites $p=0.511)$ and $10 \mathrm{~h}$ (fingertips $p=0.091$, split skin donor sites $p=0.511$ ). By comparing of all fluid samples with the respective serum samples, we observed a significant increase at $5 \mathrm{~h}(p=0.034)$ and $10 \mathrm{~h}(p=0,041)$. However, this effect was reversed at $15 \mathrm{~h}$. A significant decrease in MSC proliferation of both wound fluids combined compared to the controls was seen starting at $45 \mathrm{~h}$ of incubation $(p=0.046)$ and later (see Fig. 6). The proliferation of HS27 FBs showed initially a slow decrease in both fluids, which was significant in the fingertip fluid group

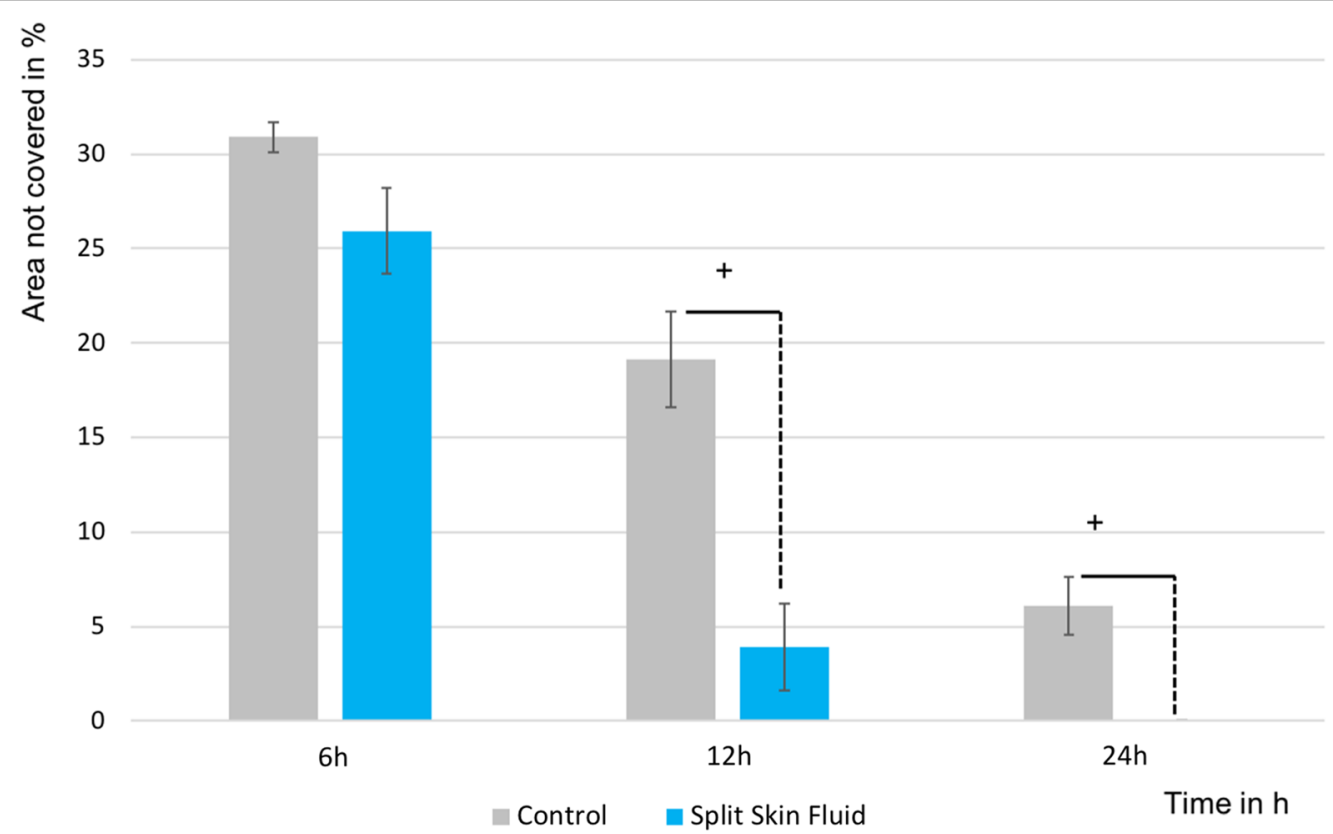

Fig. 4 HS27 FB migration in the in vitro wound-healing assay. All groups in mean \pm SEM. ${ }^{+} p<0.05$ mean split skin fluids vs. mean controls

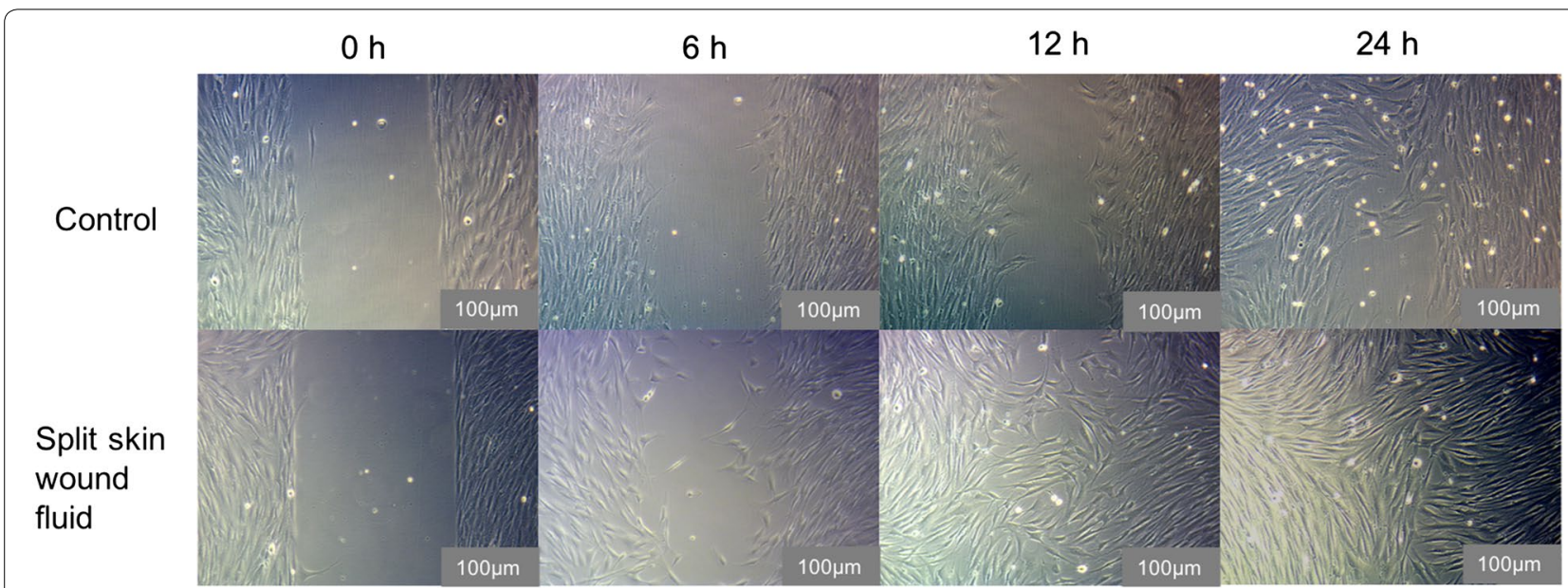

Fig. 5 Representative microscopic images of cell migration at different time points in the in vitro wound-healing assay using 100-times magnification (scale bar size: $100 \mu \mathrm{m}$ ) 


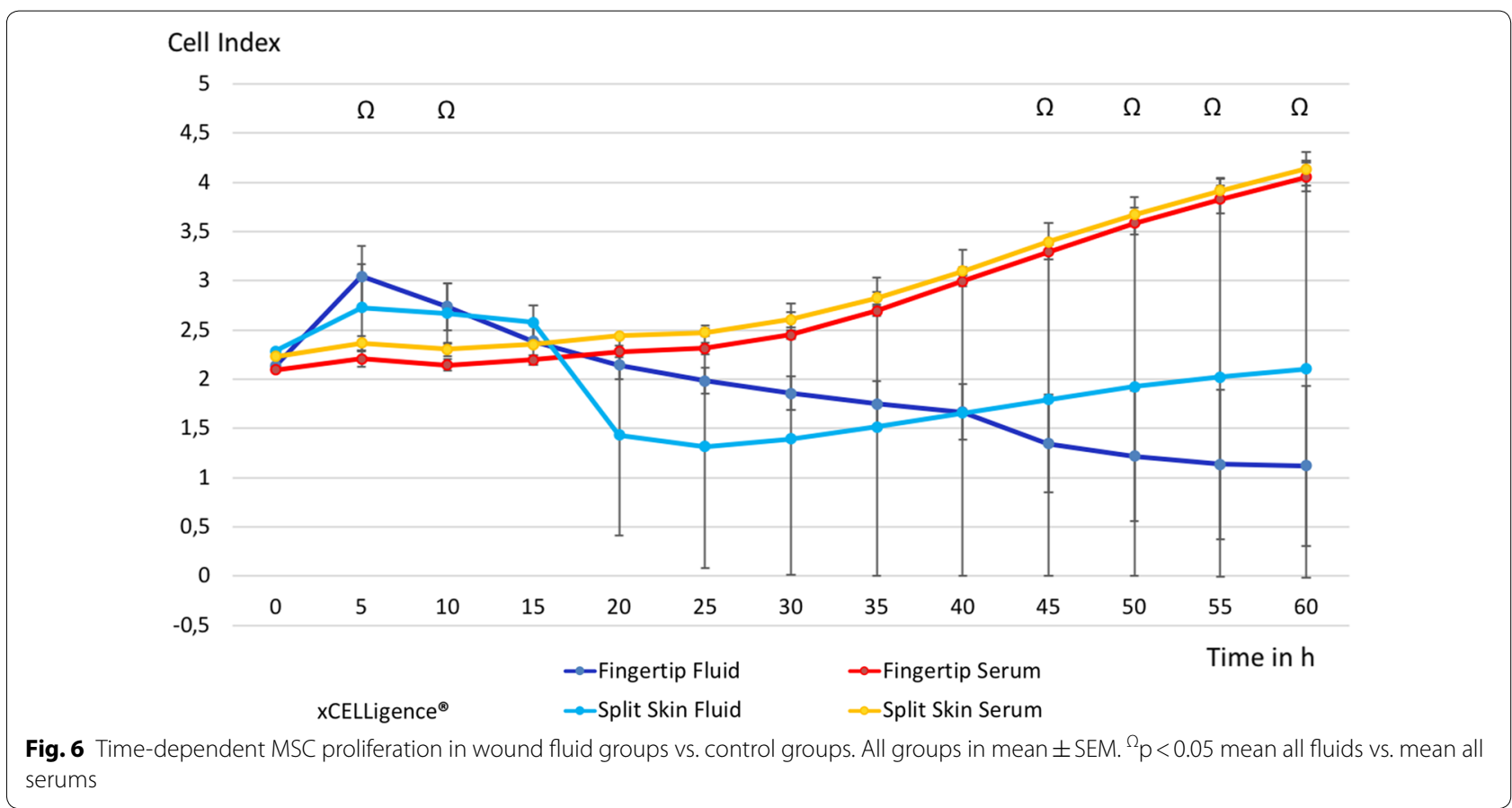

compared to the control group at $15 \mathrm{~h}(p=0.012)$ and $20 \mathrm{~h}(p=0.030)$. The pooled analysis of HS27 FB proliferation of all fluids compared to all serum controls was significantly decreased from $15 \mathrm{~h}(p=0.022)$ to $25 \mathrm{~h}(0.039)$, continuing to be so at $40 \mathrm{~h}(p=0.044)$ onward (see Fig. 7).

\section{Cell metabolism/proliferation II (Alamarblue)}

HS27 FBs were significantly reduced in the fingertip fluid group compared to respective controls $(p=0.006)$, whereas MSCs were significantly decreased only in the split skin fluid group compared to controls $(p=0.0448)$. We saw a significant decrease in MSC proliferation exposed to both combined wound fluids compared to blood serum controls $(p=0.008)$. HS27 FB proliferation also decreased in both pooled fluid groups significantly compared to the controls $(p=0.003)$ after 3 days of sample incubation (see Fig. 8).

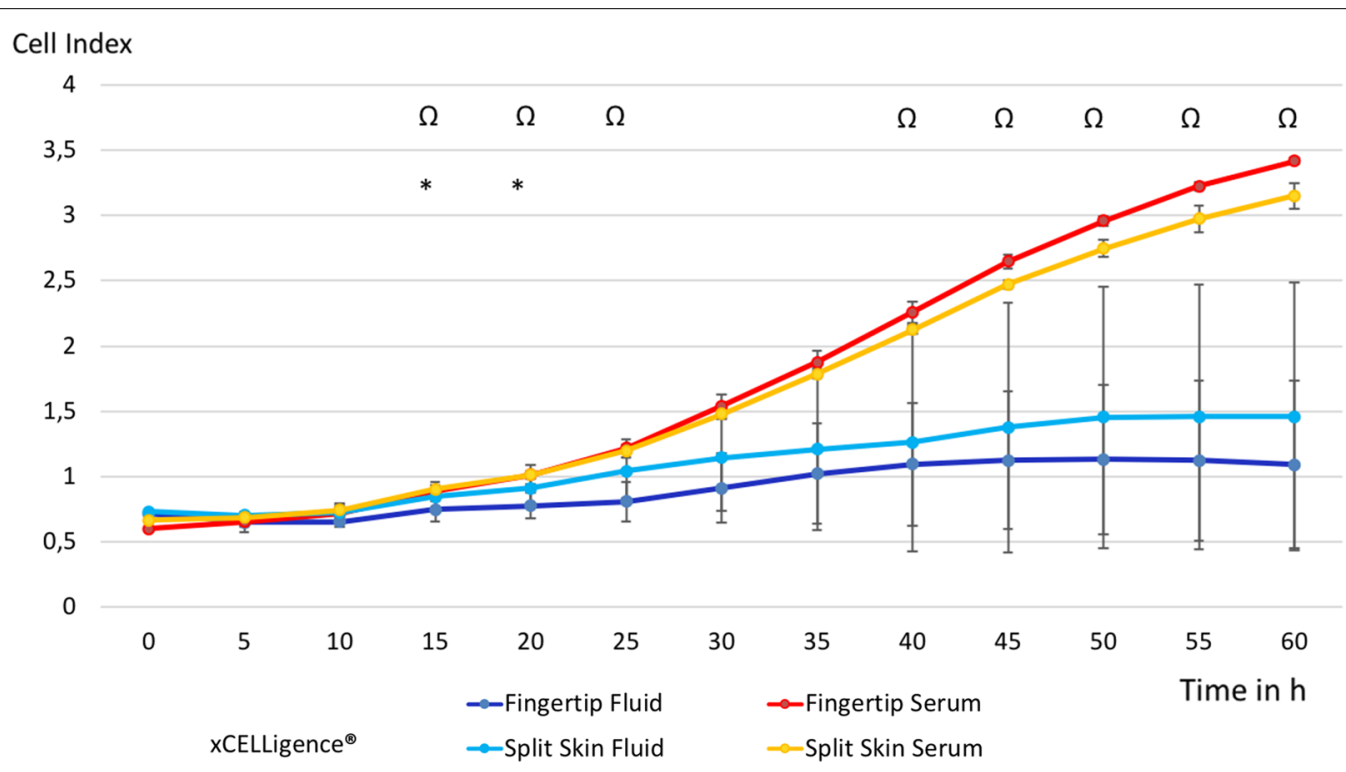

Fig. 7 Time-dependent HS27 FBs proliferation in wound fluid groups vs. control groups. All groups in mean $\pm S E M .{ }^{*} p<0.05$ mean fingertip fluids vs. mean fingertip serums. ${ }^{\Omega} p<0.05$ mean all fluids vs. mean all serums 


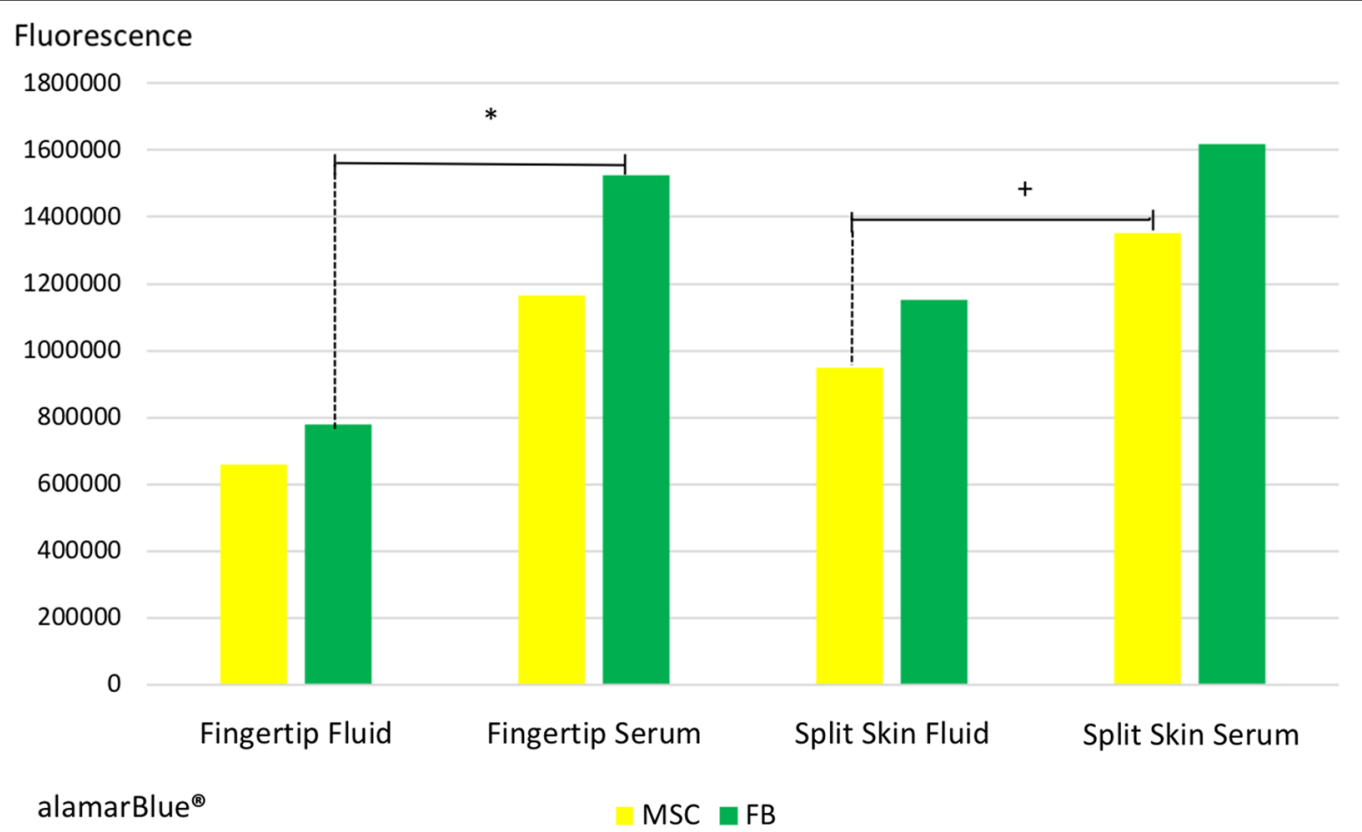

Fig. 8 Proliferation of MSCs and HS27 FBs after 3 days of sample incubation. All groups in mean \pm SEM. ${ }^{*} p<0.01$ mean fingertip fluids vs. mean fingertip serums. ${ }^{+} p<0.05$ mean split skin fluids vs. mean split skin serums

We did not observe any statistically significant difference in the behavior of mesenchymal stem cells and fibroblasts between samples from fingertip or split skin donor site wound fluids.

\section{Discussion}

A moist wound environment stimulates fibroblast proliferation, enhances the expression of growth factors, and induces angiogenesis, which finally leads to a faster regeneration [22, 23]. In addition, the formation of scars, as well as scar quality in general is improved, achieving a better functional and aesthetic outcome [24]. These effects on scars might be due to a shorter inflammation and proliferation phase in moist dermal wound healing compared to dry dressing changes [25]. In line with this hypothesis, Ksander et al. demonstrated that moisture vapor-permeable dressings inhibited the deposition of granulation tissue and collagen compared to air-exposed wounds in animal models. Histologic results of these wounds showed large amounts of fibrous connective tissue with mononuclear and polymorphonuclear cells in air-exposed wounds, whereas wounds treated with moist dressings showed a lack of these tissues and cells as well as decreased inflammation [26]. O'Shaughnessy et al. demonstrated that occlusion reduces epidermal water loss and may restore the homeostasis of the epidermal barrier, which decreases hypertrophic scarring and inflammation-specific cells like macrophages [27]. However, the interplay of FBs and MSCs in moist wound healing and the influence of wound exudate on local cells in the wound bed is incompletely understood.

The formation of granulation tissue and cellular interactions in the inflammatory and proliferation phases seems to differ significantly in moist wound healing compared to air-exposed wounds $[25,26,28]$. Fibroplasia and the creation of granulation tissue are mainly dependent on fibroblasts, which are the dominant cell type by day 4 of wound healing and peak at 7-14 days after injury [29, 30]. Platelet-derived growth factor (PDGF), basic fibroblast growth factor (bFGF), and transforming growth factor- $\beta$ (TGF- $\beta$ ) modulate the initial migration and proliferation of fibroblasts, which then reorganize and replace the provisional matrix through synthesis and the release of collagen [31, 32]. Finally, in remodeling which takes up to 2 years, the provisional matrix is restructured by matrix metalloproteinases to increase tensile strength, resulting in a scar [3].

As important as fibroblasts are for the formation of the proliferative tissue, the production of collagen and finally its differentiation into myofibroblasts to allow wound contraction is mainly induced by MSCs, which are the important modulators every step of the way [33]. In the inflammatory phase, MSCs act as anti-inflammatory agents by increasing anti-inflammatory cytokines like interleukin-10 (IL-10) and IL-4, as well as prohibiting the secretion of pro-inflammatory cytokines like TNF- $\alpha$ and Interferon- $\gamma$ [34]. In chronic wounds, all woundhealing phases are prolonged, with immense infiltration 
by neutrophil granulocytes [35]. MSCs can interrupt this cycle and allow wound healing by decreasing the inflammatory state, by promoting cell migration and proliferation as well as by induction of angiogenesis [36]. Our results demonstrate a trend towards an increase in wound-healing quality, where a strong migration of MSCs and fibroblasts possibly allow the multiple tasks of these cells to take place, but limiting an overabundance of fibroblasts, which is known to be found in hypertrophic scars [4].

MSCs act predominantly by paracrine signaling and can secrete cytokines and growth factors like PDGF, vascular endothelial growth factor (VEGF), epidermal growth factor (EGF), bFGF, keratinocyte growth factor (KGF), and TGF- $\beta$, thus modulating the proliferative phase of wound healing [36]. Studies showed that medium conditioned with MSCs or MSCs alone induces dermal fibroblasts to increase the rate of wound closure and that MSCs stimulate the proliferation of fibroblasts, endothelial cells, and keratinocytes in vitro [37]. In response to MSC stimulation, collagen type I is increased by dermal fibroblasts, thus accelerating wound closure [37]. Taken these findings together, MSCs may directly influence a decrease in scar formation by inducing organized extracellular matrix (ECM) deposition [33].

\section{Scar and wound modulation by occlusive dressings}

Recent studies showed that hypoxic stimuli seem to mobilize MSCs from the wound bed and that continuous hypoxia increases MSC mobilization by supposedly upregulation of hypoxia-induced factor- $1 \alpha$ (HIF- $1 \alpha$ ) [38]. In our study, we demonstrated a significant increase of MSC mobilization when exposed to fluid from OD wounds, possibly showing one more factor involved in modulating wound repair. Here, we observed a stronger increase of MSC migration in the fingertip fluid group as in the occlusive-dressed split skin fluid group. As MSC motility decreases after reaching a plateau in our experiments, there seem to be further mechanisms in the regulation of MSC activity involved. Occlusive dressings, which maintain a hypoxic wound environment, could be responsible for the observed positive effects on wound healing $[14,15]$.

It would have been very interesting to study the contents of the secretome in our wound fluids in more detail, but unfortunately, we were restricted by the amount of fluid that could be obtained from our patients. Per patient, we only could obtain around $90 \mu \mathrm{l}$ of fluid, so we had to decide to either study the proteomic content or do cell-culture analysis. Here, we decided to focus on the cell behavior modulation of fibroblasts and MSCs. Fortunately, there are already data available about the contents of such wound fluids: Vogt et al. analyzed wound fluid from occlusive-dressed fingertip injuries on growth factors and found upregulated bFGF, epidermal growth factor (EGF), interleukin- $1 \alpha$ (IL- $1 \alpha)$, and TGF- $\beta 2$ compared to blood serum values, which could be a reason why ODs on fingertip injuries show a strong regenerative potential [39]. It was hypothesized that wounds heal faster due to fibroblast and keratinocyte proliferation, increased angiogenesis, and growth factor expression $[22,23]$. As fibroplasia and the formation of granulation tissue mainly bases on an initial burst of fibroblast activity, scar quality should not be increased due to an overabundance of proliferating fibroblasts, which are often seen in hypertrophic scars [35]. Our results show that fibroblast proliferation seems to be inhibited by occlusive-dressed wound fluids, which could be another major factor to initiate a favorable scar modulation process. These data are corroborated by a recent study, showing that inhibiting a known-scar-forming fibroblast lineage during wound healing did not lead to a change of healing rates during the initial days of wound healing. However, a significant difference in wound size developed by day 9 after wounding, with larger and less healed wounds in the treated cohorts. Most importantly, treated wounds showed significantly reduced final scar size after completion of wound healing [40]. Similarly, we could observe a spike of fibroblast mobility in the first $10 \mathrm{~h}$ after sample incubation, which afterwards decreased significantly. As fibroblasts are important players in the wound-healing process, their active role in the inflammatory and proliferative phase of wound healing is essential [35]. In dry wound healing, a fast wound closure is important to minimize fluid loss and reduce the risk of infection, thus an increased fibroblast proliferation and activity is necessary to minimize these risks, but leading to a scar [1]. A superficial occlusive barrier, allowing wound fluid to cover the wound, seems to inhibit excessive fibroblast proliferation, as we could show in our study. Interestingly, this effect was more pronounced in the fingertip fluid samples as in the split skin fluid samples, which could be responsible for the good clinical outcomes observed in occlusively dressed fingertip injuries. In addition, split skin fluids showed a significantly decreased MSC proliferation after 3 days, which was not that prominent in the fingertip fluid group, suggesting that also other factors contribute to the positive effects of ODs in wound healing [25].

\section{Limitations}

Our results were generated in a simplified in vitro model of cell migration and proliferation. This is limited by several factors: the wound fluid is only administered once in the model, while it is presumably constantly produced in the in vivo wound situation. Thus, the results in the early hours of the experiment may reflect the 
wound environment better than the later data. In vivo, the wound is an injured 3D-tissue consisting of extracellular matrix and a multitude of cells that constantly interact with each other through autocrine, paracrine, electrical, and mechanical cues that are not reproduced in the model. On the other hand, this approach allowed us to isolate effects of the wound fluid on two specific cell types that are thought to be important in wound healing, which is not as easily possible in a more complex model.

\section{Conclusion}

Using advanced cell surveillance technology, we could demonstrate a time-dependent and cell-type-related effect of wound fluid on migration and proliferation of mesenchymal stem cells and fibroblasts. This timeresolved information revealed cell behavior that is nearly impossible to study in endpoint measurements. MSCs are important modulators of the proliferation stage in wound healing and play an important role in the formation of scar tissue. The early activation of MSC migration could modulate initial tissue composition and thereby scar tissue formation. Fibroblast proliferation seems to be inhibited in occlusively dressed wounds and may improve the organization of collagen structure on the wound. This well-orchestrated interplay between stromal cells may be partially responsible for the improved wound-healing process and scar quality, which are seen in fingertip injuries and split skin donor sites treated under occlusive conditions.

\section{Abbreviations}

ECM: extracellular matrix; ODs: occlusive dressings; MSCs: mesenchymal stem cells; ASCs or ADSCs: adipose-derived stem cells.

\section{Authors' contributions}

MKC: substantial contributions to conception, design, acquisition, analysis and interpretation of data, and drafting of the manuscript. UH: substantial acquisition, analysis, and interpretation of data. MK: substantial acquisition, analysis, and interpretation of data. EMH: substantial acquisition, analysis, and interpretation of data. FW: substantial acquisition, analysis, and interpretation of data. RG: substantial contributions to conception and design. HGM: substantial contributions to conception, design, and critically important revision of the manuscript for intellectual content. DD: analysis and interpretation of data, and critically important revision of the manuscript for intellectual content. HE: substantial contributions to conception, design, acquisition, analysis and interpretation of data, and critically important revision of the manuscript for intellectual content. AFS: substantial contributions to conception, design, acquisition, analysis and interpretation of data, and critically important revision of the manuscript for intellectual content. All authors read and approved the final manuscript.

\footnotetext{
Author details

1 Department for Plastic Surgery and Hand Surgery, Klinikum Rechts der Isar, Technical University Munich, Ismaninger Str.22, 81675 Munich, Germany. 2 Department for Hand Surgery, Plastic Surgery and Aesthetic Surgery, Ludwig-Maximilian-University Munich, Munich, Germany. ${ }^{3}$ Department for Trauma Surgery, Orthopedic Surgery and Plastic Surgery, University Medical Center Goettingen, Goettingen, Germany.
}

\section{Acknowledgements}

The authors want to thank Jan Thorsten Schantz for his help in planning the study and Josef Freund for his help with the Xcelligence technology.

\section{Competing interests}

The authors declare that they have no competing interests.

\section{Availability of data and materials}

All data and materials are available from the corresponding author on reasonable request.

\section{Consent for publication}

Not applicable.

\section{Ethics approval and consent to participate}

The study protocol conformed to the guidelines of the 1975 Declaration of Helsinki as reflected in the approval of our local ethics committee (No. 527/15). All patients' signed informed consent forms prior to participation in our study.

\section{Funding}

The study was funded by the Division of Experimental Plastic Surgery, Klinikum rechts der Isar, Munich, Germany without any commercial interests or obligations.

\section{Publisher's Note}

Springer Nature remains neutral with regard to jurisdictional claims in published maps and institutional affiliations.

Received: 6 November 2018 Accepted: 15 December 2018

Published online: 26 December 2018

\section{References}

1. Eming SA, Krieg T, Davidson JM. Inflammation in wound repair: molecular and cellular mechanisms. J Invest Dermatol. 2007;127(3):514-25.

2. Li J, Chen J, Kirsner R. Pathophysiology of acute wound healing. Clin Dermatol. 2007;25(1):9-18.

3. Singer AJ, Clark RA. Cutaneous wound healing. N Engl J Med. 1999;341(10):738-46.

4. Ferguson MW, Whitby DJ, Shah M, Armstrong J, Siebert JW, Longaker MT. Scar formation: the spectral nature of fetal and adult wound repair. Plast Reconstr Surg. 1996:97(4):854-60.

5. Gurtner GC, Werner S, Barrandon Y, Longaker MT. Wound repair and regeneration. Nature. 2008;453(7193):314-21.

6. Lorenz HP, Longaker MT, Perkocha LA, Jennings RW, Harrison MR, Adzick NS. Scarless wound repair: a human fetal skin model. Development. 1992;114(1):253-9.

7. Lo DD, Zimmermann AS, Nauta A, Longaker MT, Lorenz HP. Scarless fetal skin wound healing update. Birth Defects Res C Embryo Today. 2012;96(3):237-47.

8. Ferguson MW, O'Kane S. Scar-free healing: from embryonic mechanisms to adult therapeutic intervention. Philos Trans R Soc Lond B Biol Sci. 2004;359(1445):839-50

9. Shih B, Garside E, McGrouther DA, Bayat A. Molecular dissection of abnormal wound healing processes resulting in keloid disease. Wound Repair Regen. 2010;18(2):139-53.

10. Hoigne D, Hug U, Schurch M, Meoli M, von Wartburg U. Semi-occlusive dressing for the treatment of fingertip amputations with exposed bone: quantity and quality of soft-tissue regeneration. J Hand Surg Eur. 2014;39(5):505-9.

11. Hinman $\mathrm{CD}$, Maibach $\mathrm{H}$. Effect of air exposure and occlusion on experimental human skin wounds. Nature. 1963;200:377-8.

12. Soderberg T, Nystrom A, Hallmans G, Hulten J. Treatment of fingertip amputations with bone exposure. A comparative study between surgical and conservative treatment methods. Scand J Plast Reconstr Surg. 1983;17(2):147-52. 
13. Mennen U, Wiese A. Fingertip injuries management with semi-occlusive dressing. J Hand Surg Br. 1993;18(4):416-22.

14. Alvarez OM, Mertz PM, Eaglstein WH. The effect of occlusive dressings on collagen synthesis and re-epithelialization in superficial wounds. J Surg Res. 1983;35(2):142-8.

15. Winter GD. Formation of the scab and the rate of epithelization of superficial wounds in the skin of the young domestic pig. Nature. 1962;193:293-4

16. Hadjipanayi E, Kuhn PH, Moog P, Bauer AT, Kuekrek H, Mirzoyan L, et al. The fibrin matrix regulates angiogenic responses within the hemostatic microenvironment through biochemical control. PLOS ONE. 2015;10(8):e0135618.

17. Hadjipanayi E, Schilling AF. Regeneration through autologous hypoxia preconditioned plasma. Organogenesis. 2014;10(2):164-9.

18. Hadjipanayi E, Bauer AT, Moog P, Salgin B, Kuekrek H, Fersch B, et al. Cell-free carrier system for localized delivery of peripheral blood cell-derived engineered factor signaling: towards development of a one-step device for autologous angiogenic therapy. J Control Release. 2013;169(1-2):91-102.

19. Muhldorfer-Fodor $M$, Hohendorff $B$, Vorderwinkler KP, van Schoonhoven J, Prommersberger KJ. Treatment of fingertip defect injuries with a semiocclusive dressing according to Mennen and Wiese. Oper Orthop Traumatol. 2013;25(1):104-14

20. Kindzierski V. External stimulation of differentiated and undifferentiated cells in vitro. Munich: Technical University Munich; 2012.

21. Schneider S, Unger M, van Griensven M, Balmayor ER. Adipose-derived mesenchymal stem cells from liposuction and resected fat are feasible sources for regenerative medicine. Eur J Med Res. 2017;22(1):17.

22. Katz MH, Alvarez AF, Kirsner RS, Eaglstein WH, Falanga V. Human wound fluid from acute wounds stimulates fibroblast and endothelial cell growth. J Am Acad Dermatol. 1991:25(6 Pt 1):1054-8.

23. Madden MR, Nolan E, Finkelstein JL, Yurt RW, Smeland J, Goodwin CW, et al. Comparison of an occlusive and a semi-occlusive dressing and the effect of the wound exudate upon keratinocyte proliferation. J Trauma. 1989;29(7):924-30 (discussion 30-1).

24. Atiyeh BS, Amm CA, El Musa KA. Improved scar quality following primary and secondary healing of cutaneous wounds. Aesthetic Plast Surg. 2003;27(5):411-7.

25. Dyson M, Young S, Pendle CL, Webster DF, Lang SM. Comparison of the effects of moist and dry conditions on dermal repair. J Invest Dermatol. 1988;91(5):434-9.

26. Ksander GA, Pratt BM, Desilets-Avis P, Gerhardt CO, McPherson JM. Inhibition of connective tissue formation in dermal wounds covered with synthetic, moisture vapor-permeable dressings and its reversal by transforming growth factor-beta. J Invest Dermatol. 1990;95(2):195-201.
27. O'Shaughnessy KD, De La Garza M, Roy NK, Mustoe TA. Homeostasis of the epidermal barrier layer: a theory of how occlusion reduces hypertrophic scarring. Wound Repair Regen. 2009;17(5):700-8.

28. Vogt PM, Andree C, Breuing K, Liu PY, Slama J, Helo G, et al. Dry, moist, and wet skin wound repair. Ann Plast Surg. 1995;34(5):493-9 (discussion 9-500).

29. Gray AJ, Bishop JE, Reeves JT, Laurent GJ. A alpha and B beta chains of fibrinogen stimulate proliferation of human fibroblasts. J Cell Sci. 1993;104(Pt 2):409-13.

30. Barry FP. Biology and clinical applications of mesenchymal stem cells. Birth Defects Res C Embryo Today. 2003;69(3):250-6.

31. Robson MC, Dubay DA, Wang X, Franz MG. Effect of cytokine growth factors on the prevention of acute wound failure. Wound Repair Regen. 2004;12(1):38-43.

32. Pajulo OT, Pulkki KJ, Lertola KK, Alanen MS, Reunanen MS, Virtanen RV, et al. Hyaluronic acid in incision wound fluid: a clinical study with the Cellstick device in children. Wound Repair Regen. 2001;9(3):200-4.

33. Maxson S, Lopez EA, Yoo D, Danilkovitch-Miagkova A, Leroux MA. Concise review: role of mesenchymal stem cells in wound repair. Stem Cells Transl Med. 2012;1(2):142-9.

34. Aggarwal S, Pittenger MF. Human mesenchymal stem cells modulate allogeneic immune cell responses. Blood. 2005;105(4):1815-22.

35. Diegelmann RF, Evans MC. Wound healing: an overview of acute, fibrotic and delayed healing. Front Biosci. 2004;9:283-9.

36. Gnecchi M, Zhang Z, Ni A, Dzau VJ. Paracrine mechanisms in adult stem cell signaling and therapy. Circ Res. 2008;103(11):1204-19.

37. Smith AN, Willis E, Chan VT, Muffley LA, Isik FF, Gibran NS, et al. Mesenchymal stem cells induce dermal fibroblast responses to injury. Exp Cell Res. 2010;316(1):48-54

38. Liu L, Yu Q, Lin J, Lai X, Cao W, Du K, et al. Hypoxia-inducible factor-1alpha is essential for hypoxia-induced mesenchymal stem cell mobilization into the peripheral blood. Stem Cells Dev. 2011;20(11):1961-71.

39. Vogt PM, Wagner D, Lehnhardt M, Peter FW, Steinau HU. Monitoring growth factors during wound healing as the basic principle of effective clinical growth factor therapy? Langenbecks Arch Chir Suppl Kongressbd. 1997;114:1373-5.

40. Rinkevich Y, Walmsley GG, Hu MS, Maan ZN, Newman AM, Drukker M, et al. Skin fibrosis. Identification and isolation of a dermal lineage with intrinsic fibrogenic potential. Science. 2015;348(6232):aaa2151.
Ready to submit your research? Choose BMC and benefit from:

- fast, convenient online submission

- thorough peer review by experienced researchers in your field

- rapid publication on acceptance

- support for research data, including large and complex data types

- gold Open Access which fosters wider collaboration and increased citations

- maximum visibility for your research: over $100 \mathrm{M}$ website views per year

At BMC, research is always in progress.

Learn more biomedcentral.com/submissions 